\title{
Report of Breakout Group 2. How Will We Provide Improved Varieties of Specialty Minor and Subsistence Crops in the Future?
}

\author{
Cholani Weebadde \\ Department of Horticulture, Michigan State University, East Lansing, MI 48824 \\ Clarice Mensah \\ Department of Crops and Soils, Michigan State University, East Lansing, MI 48824
}

There is growing concern about who will breed the specialty crops grown commercially on a limited acreage with niche markets, or the subsistence crops that are widely grown by low-income producers for food, but provide them with little income. There is little public support for these crops and they do not provide a significant economic return to be bred by private industry. The crops that will be most severely affected by the lack of breeding programs will most likely include the tuber crops such as sweet potatoes that are not priority crops with either international agriculture research centers (IARCs) or the private sector, and the long generation tree crops such as pecans, almonds, and walnuts, where the return on investments takes a very long time. Government-supported crops such as sugar beet and cotton could also suffer the same fate, if subsidies are removed.

The biggest challenge faced by plant breeders of specialty and subsistence crops is the lack of long-term funding for varietal development. For many crops, there are not enough breeders interacting for rapid, sustained progress. Germplasm will eventually be lost both locally and internationally if specialty crop breeding programs are discontinued due to unavailability of funds. It is essential that regional collaborations are formed among researchers with similar crop interests to make their breeding efforts as efficient as possible, minimize cost and aid in the acquisition of grant funds.

\section{NEED TO GENERATE ADDITIONAL SUPPORT}

New sources of funding for specialty crop breeding should be developed within the university, state and federal funding systems. Not only is the continued breeding of these crops critical to the well being of millions of people, but specialty crop breeders are playing an increasingly important role in university training, as the breeding of the major agronomic crops is shifted to private industry. Federal grant programs should be established that support graduate fellowships to work on specialty crops. More licensing of varieties by universities could generate additional funding to support specialty plant breeding programs, if the funds are allowed to flow back to the breeding program. The establishment of endowments, preferably matched dollar to dollar by funds from public institutions, is another option worth exploring.

State and federal funding agencies also must be encouraged to develop new initiatives to provide funding for specialty crop breeding research. Support is needed to directly stimulate research collaborations among specialty crop breeders. Research support can be linked to other crop funding efforts by supporting whole families of agronomically important crops and by supporting research on pathogens and pests that attack a broad range of related and unrelated crops. Examples of these are the USDA-National Research Initiative (NRI) program on the genomics of Rosaceous crops which included the specialty crops tart cherry and strawberry, and the recent federal initiative on fusarium head blight or scab that is based primarily on bread wheat but also supports work on the specialty crop durum wheat. Another example is the National Sclerotinia Initiative, which provides funding for a broad range of specialty crops including canola, dry bean, lentil, and sunflower.

\section{NEED TO RAISE AWARENESS}

Public awareness of the importance of specialty and subsistence crops must to be raised considerably if these crops are to obtain long term, sustained funding for breeding. Many specialty crops are neglected by the private sector due to insufficient return on investment, and breeding accomplishments go unnoticed by the general public leading to little public support. The industries that use specialty crops need to be made more aware of the importance of plant breeding and encouraged to fund these efforts. Models of industry support of public breeding programs can be found in the support for pepper breeding by the Kalamazoo Spice Company and oats by the Quaker Oats Company.

Policy makers at the national and international levels need to be more aware of the importance of specialty and subsistence crop breeding. Consultative Group on International Agriculture Research (CGIAR) centers that currently have strong breeding programs on subsistence crops need consistent, dependable support. National agriculture research systems (NARSs) and IARCs have to take responsibility for facilitating and coordinating all crop breeding. NARCs should play the primary role in identifying and promoting these breeding efforts in the developed countries with substantial resources. In the developing countries, which lack sufficient numbers of breeders and technology, the IARCs need to take leadership in breeding subsistence crops. Part of their efforts can come through participatory plant breeding, where farmers test advanced selections to reduce costs, but central breeding efforts will still need to be maintained. 